\title{
The combination of pure oesophageal atresia with an associated missed $\mathrm{H}$-type tracheo-oesophageal fistula
}

\author{
Ramnik V Patel, ${ }^{1,2}$ Owen Greene, ${ }^{3}$ Sandeep Motiwale, ${ }^{3}$ Shailinderjit Singh ${ }^{3}$
}

${ }^{1}$ Department of Paediatric Urology, University College London Hospitals NHS Foundation Trust, London, UK ${ }^{2}$ Department of Paediatric Urology, Great Ormond Street Children Hospital NHS Trust, London, UK

${ }^{3}$ Department of Paediatric Surgery, QMC, Nottingham, UK

\section{Correspondence to} Ramnik V Patel,

ramnik@doctors.org.uk
To cite: Patel RV, Greene $\mathrm{O}$ Motiwale S, et al. BMJ Case Rep Published online:

[please include Day Month Year] doi:10.1136/bcr-2013200198

\section{DESCRIPTION}

A 7-year-old girl presented with recurrent lower respiratory tract infections, coughing episodes associated with liquids and recurrent abdominal distension. There was maternal polyhydramnios and absent gastric bubble on antenatal anomaly scan with an antenatal diagnosis of pure oesophageal atresia (OA). There was no family history of OA for three generations on maternal or paternal side. At birth she had babygram showing arrested orogastric tube in the upper blind pouch and gasless abdomen, no vertebral anomalies and spinal ultrasound, echocardiogram and renal ultrasound were all normal. Voiding cystourethrogram with distal loopogram demonstrated bilateral vesicoureteral reflux (VUR). The chromosomal studies revealed normal 46XX karyotype and the patient had genetic counselling. She was born with partial VACTREL (Vertebral, Ano-rectal malformation, Cardiac anomalies, Tracheal anomalies, Esophageal anomalies and Limb anomalies) association comprising pure oesophageal atresia, anorectal malformation with rectovestibular fistula and bilateral VUR and treated elsewhere. She underwent gastrostomy and left descending colostomy at birth. The following week, she underwent posterior sagittal anorectoplasty with colostomy closure. At 2 months, she underwent repair of the long gap OA with gastric interposition, closure of gastrostomy and pyloroplasty as delayed primary closure proved impossible. Postoperatively she developed a leak at the gastro-oesophageal anastomosis which was treated conservatively. In the following 2 year she lived abroad and was only followed up within the UK on an intermittent basis. She underwent upper gastrointestinal contrast twice during this period which showed no evidence of a stricture but demonstrated oesophageal reflux and the recent one suspicious of an $\mathrm{H}$-tracheooesophageal fistula (H-TOF, figure 1). She underwent combined bronchoscopy and an upper gastrointestinal endoscopy. This demonstrated a large H-type fistula, which could be easily cannulated,
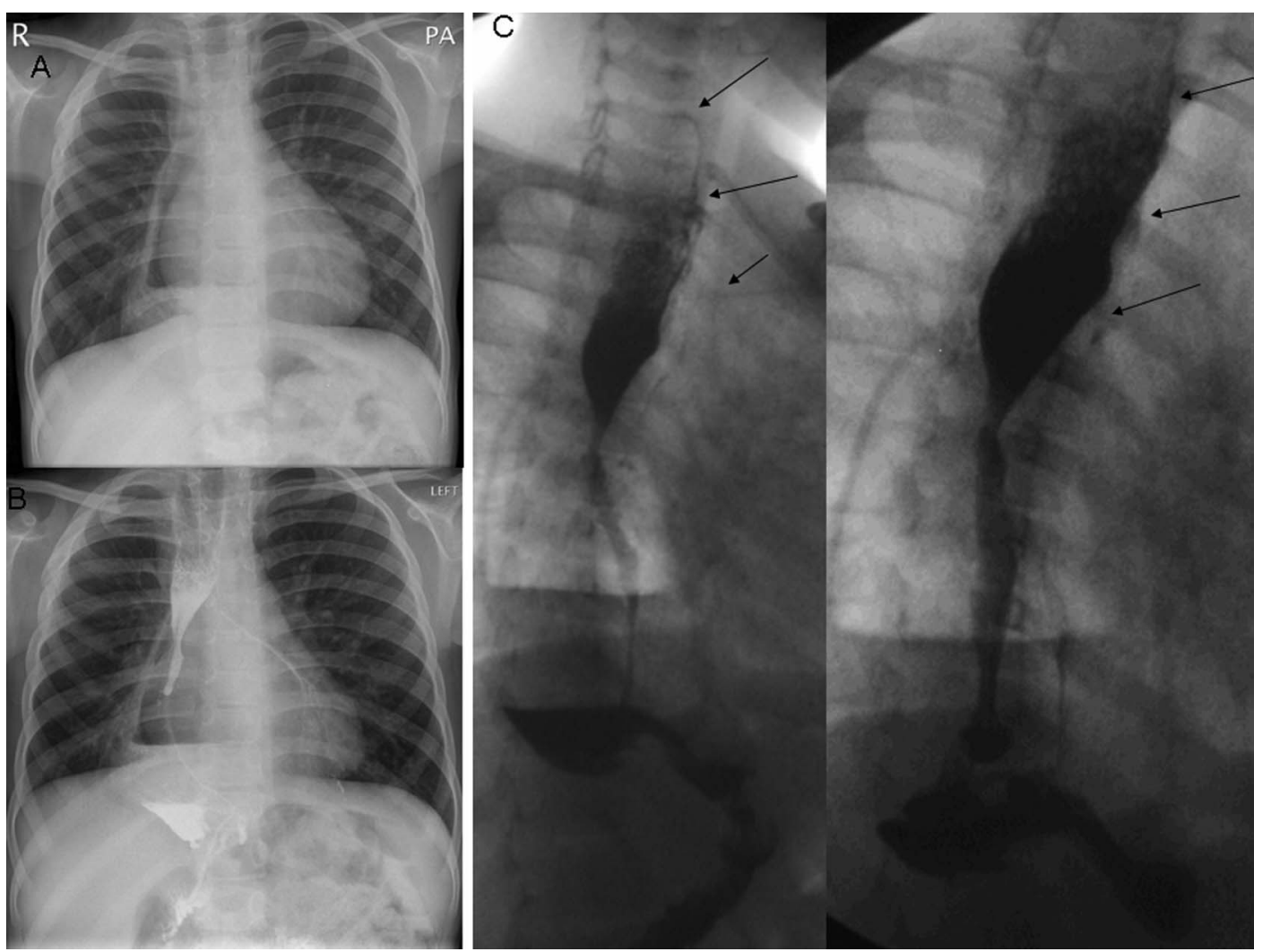

Figure 1 (A) Chest X-ray showing gastric transposition of the stomach into the chest. Note the excessive abdominal gas-filled loops. (B) Initial upper gastrointestinal (UGI) contrast. (C) Repeat UGI contrast showing suspicious fistula tract shown with arrows. 
that entered the oesophagus at $15 \mathrm{~cm}$. She underwent ligation of H-TOF with interposition of a muscle flap via a right-sided neck incision after using the fibre optic light of the oesophagoscope to visualise the fistula intraoperatively. The postoperative period passed uneventful and she made a full recovery. She is asymptomatic, well and thriving at 6-year follow-up. Combined OA and $\mathrm{H}-\mathrm{TOF}$ are very rare. The triad of symptoms, contrast study and endoscopy are diagnostic. ${ }^{1-3}$

\section{Learning points}

- Combination of pure oesophageal atresia (OA) and $\mathrm{H}$-tracheo-oesophageal fistula (H-TOF) is very rare and should be suspected if there is a triad of symptoms of recurrent lower respiratory tract infections, coughing and/or choking episodes mainly with liquids and recurrent abdominal distension due to preferential high distal runoff of air from the tracheo-oesophageal fistula caused by low resistance in the oesophagus as compared with stiff lungs due to repeated aspiration pneumonia and associated fibrosis.

- Upper gastrointestinal contrast study needs special technique to visualise the fistula and bronchoscopy is diagnostic. This allows ureteric catheter cannulation which helps in easy identification at surgery.

- Use of fibre optic light source of an endoscope provides brilliant transillumination and easy identification of the fistula and recurrent laryngeal nerve during surgery avoiding injury to this vital nerve.
Contributors All authors have contributed in the clinical management of this patient and have actively participated in the preparation of the manuscript, searching the literature, and preparing the illustrations and appraising the final draft.

Competing interests None.

Patient consent Obtained.

Provenance and peer review Not commissioned; externally peer reviewed.

\section{REFERENCES}

1 Kane TD, Atri P, Potoka DA. Triple fistula: management of a double tracheoesophageal fistula with a third H-type proximal fistula. J Pediatr Surg 2007;42:E1-3.

2 Crabbe DC. Isolated tracheo-oesophageal fistula. Paediatr Respir Rev 2003:4:74-8.

3 Johnson AM, Rodgers BM, Alford B, et al. Esophageal atresia with double fistula: the missed anomaly. Ann Thorac Surg 1984;38:195-200.

Copyright 2013 BMJ Publishing Group. All rights reserved. For permission to reuse any of this content visit http://group.bmi.com/group/rights-licensing/permissions.

BMJ Case Report Fellows may re-use this article for personal use and teaching without any further permission.

Become a Fellow of BMJ Case Reports today and you can:

- Submit as many cases as you like

- Enjoy fast sympathetic peer review and rapid publication of accepted articles

- Access all the published articles

- Re-use any of the published material for personal use and teaching without further permission

For information on Institutional Fellowships contact consortiasales@bmjgroup.com

Visit casereports.bmj.com for more articles like this and to become a Fellow 